\title{
Amifostine is a Nephro-Protectant in Patients Receiving Treatment with Cisplatin- Myth, Mystery or Matter-of-Fact?
}

\author{
Sin Sil Ha', Kazi Rubaina', Chung-Shien Lee ${ }^{1,2}$, Veena John ${ }^{2}$, Nagashree Seetharamu ${ }^{2 *}$ \\ 'St. John's University, College of Pharmacy and Health Sciences, Department of Clinical Health Professions, 8000 Utopia Parkway, Queens, NY 11439 , USA \\ ${ }^{2}$ Division of Medical Oncology and Hematology, Northwell Health Cancer Institute, Donald \& Barbara Zucker School of Medicine at Hofstra/Northwell, 450 \\ Lakeville Road, Lake Success, NY 1 1042, USA.
}

\section{Article Info}

\section{Article Notes}

Received: December 22, 2020

Accepted: February 01, 2021

\section{*Correspondence:}

${ }^{*}$ Dr. Nagashree Seetharamu, Division of Medical Oncology and Hematology, Northwell Health Cancer Institute, Donald \& Barbara Zucker School of Medicine at Hofstra/Northwell, 450 Lakeville Road, Lake Success, NY 11042, USA; Email: Nseetharamu@northwell.edu.

${ }^{0} 2021$ Seetharamu N. This article is distributed under the terms of the Creative Commons Attribution 4.0 International License.

\section{Keywords}

Amifostine

Cisplatin

Nephrotoxicity

\section{Abstract}

Despite reports of amifostine possibly protecting nephrotoxicity from cisplatin, it has not been recommended by any guidelines committees or routinely prescribed in clinical practice over the past decade. In this article, we review literature and guidelines regarding use of amifostine in oncology practice for protection against adverse effects from certain chemotherapeutic agents, in particular as a nephro-protectant in patients receiving cisplatin.

\section{Background Information}

Amifostine (Ethyol) is a prodrug that is dephosphorylated by alkaline phosphatase in tissues to a pharmacologically active free thiol metabolite. This metabolite has been shown to reduce toxic effects of radiation on normal tissues ${ }^{1}$. It is also believed to mitigate the cumulative renal toxicity from cisplatin ${ }^{1}$. Selective increased concentration of the thiol metabolite of amifostine in normal tissues enables binding to and subsequently detoxifying reactive metabolites of cisplatin, thereby reducing the cumulative toxicities in particular renal toxicity from cisplatin. This thiol metabolite can also scavenge reactive oxygen species generated by exposure to either cisplatin or radiation ${ }^{1}$.

In December 2008, American Society of Clinical Oncology (ASCO) guidelines updated their recommendations on the use of amifostine as a prophylactic agent to prevent toxicity in patients receiving certain chemotherapeutic agents such as cisplatin, carboplatin and paclitaxel, and in patients receiving radiotherapy.

\section{Amifostine Use in Thrombocytopenia}

The use of amifostine is not recommended for thrombocytopenia. In 1999, the ASCO panel articulated that data were insufficient to recommend the use of amifostine for protection against thrombocytopenia. In a small randomized clinical trial with 55 patients with various malignancies, no difference was found in the median platelet count after the first cycle between amifostine and carboplatin compared to carboplatin alone $\left(144 \mathrm{X} 10^{9} / \mathrm{L}\right.$ vs. $85 \mathrm{X}$ $\left.10^{9} / \mathrm{L} ; \mathrm{p}=0.24\right)$. The overall median platelet nadir was higher in the amifostine and carboplatin group compared to carboplatin alone $\left(127 \times 10^{9} / \mathrm{L} \text { vs. } 88 \times 10^{9} / \mathrm{L} ; \mathrm{p}=0.023\right)^{2}$. In another small randomized phase II trial, there was no difference in platelet nadir or incidence of grade 3/4 thrombocytopenia in the amifostine and carboplatin group versus the control group ${ }^{3}$. However, the time to platelet 
recovery $\left(>100 \times 10^{9}\right)$ was reduced in the amifostine and carboplatin group (13.5 days vs. 21 days, $\mathrm{p}=0.04$ ). Rate of hospitalization for IV antibiotics and other supportive measures was also reduced in the amifostine and carboplatin group $(0 / 25$ vs. $6 / 25$ patient courses, $p=0.06)$, although there was no statistically significant difference in the infection incidence ${ }^{3}$. Additional randomized clinical trials (RCTs) in the early 2000s showed lack of benefit from using amifostine for preventing chemotherapy-associated thrombocytopenia.-14 The ASCO panel subsequently recommended against the use of amifostine to prevent thrombocytopenia associated with chemotherapy and radiation. ${ }^{4}$ This was based on thrombocytopenia outcomes from ten RCTs assessing the use of amifostine with chemotherapy, combined chemotherapy, or radiotherapy. ${ }^{5-14}$ Seven studies of these studies showed no statistical difference in thrombocytopenia ${ }^{5,6,8-10,12,14}$, while two reported mixed outcomes favoring control groups without amifostine, ${ }^{7,13}$ and one study favored the control group. ${ }^{11}$ Additionally, a meta-analysis that was conducted in 2014 to study the effect of amifostine in head and neck cancer patients treated with radiotherapy which, included seventeen trials and 1167 patients demonstrated no significant difference of grade 3/4 thrombocytopenia was found. ${ }^{15}$

\section{Amifostine Use in Neurotoxicity and Ototoxicity}

Similarly, due to inconsistent data and unclear clinical significance in clinical trials, the panel recommended against the use of amifostine for prevention of neurotoxicity or ototoxicity from carboplatin and cisplatin, which is a change from the 2002 recommendations. ${ }^{4}$ In a metaanalysis published in 2014, 7 RCTs ( $n=743$ ) were reviewed and it was found that only one trial had favorable outcomes based on fourteen patients receiving amifostine, but the change measured was deduced to be subclinical. Due to these results, it was concluded that the data is insufficient to determine if amifostine prevented neurotoxicity or ototoxicity. ${ }^{4,16}$ It was also found in another study with 90 ovarian cancer patients receiving paclitaxel and carboplatin that there was a difference in sensory neurotoxicity across all cycles. It was found that $48 \%$ of the amifostine arm and $45 \%$ of the control arm had grade 1 neurotoxicity, and $2 \%$ of the amifostine arm and $12 \%$ of the control arm had grade 2 neurotoxicity $(\mathrm{p}<0.001) .{ }^{13}$ However, at the end of six cycles of therapy, it was found that there is no significant difference in the frequencies of grade 1,2 , or 3 neurotoxicity in patients taking amifostine compared to control group $(69 \%, 7 \%$, and $7 \%$ vs $55 \%, 27 \%$, and $4 \%$, respectively). ${ }^{13}$

\section{Amifostine Use in Mucositis}

Due to insufficient data, ASCO also recommended against the use of amifostine for mucositis in the setting of radiation therapy for the treatment of head and neck cancer. ${ }^{4}$ This was due to lack of clinical trials comparing amifostine to placebo in radiation therapy induced mucositis. Trials that did compare amifostine with placebo or other therapies found it difficult to measure the subjective nature of mucositis and its end points. ${ }^{4,5,16-20}$ For this reason, it was concluded by the ASCO panel that blinded, placebo-control trials would be necessary for proper assessment of the efficacy of amifostine in reducing radiation induced mucositis. ${ }^{4}$

\section{Amifostine Use in Esophagitis}

Esophagitis is a new topic that has been added to the ASCO guideline, and currently data are insufficient to recommend the routine use of amifostine to prevent esophagitis in the setting of chemoradiotherapy in nonsmall-cell lung cancer (NSCLC) for the prevention of esophagitis. ${ }^{4}$ One meta-analysis analyzed 13 articles (n $=1,057$ ), which consisted of seven RCTs with one longterm follow-up study and six non-RCTs that were clinical studies, mostly phase I or II, without calculated power. ${ }^{21}$ Pooled data from six RCTs showed that the risk of $\geq$ grade 2 acute esophageal toxicity was significantly reduced by $26 \%$ (RR=0.74, 95\% CI 0.65-0.86, p<0.0001). However, the statistical heterogeneity was high (Chi-square $=36.94$, $\left.\mathrm{df}=5, \mathrm{p}<0.00001 ; \mathrm{I}^{2}=86 \%\right) .{ }^{21}$ Also, the results from two other RCTs and non-randomized trials indicated varying outcomes. ${ }^{21}$ Pooled results from five RCTs depicted that use of amifostine reduced the odds of acute pulmonary toxicity by $44 \%$ (RR=0.56, 95\%CI $0.41-0.75, \mathrm{p}=0.0001) .{ }^{21}$ Considerable statistical heterogeneity was also evident (Chi-square=17.12, df=4, $\mathrm{p}=0.002 ; \mathrm{I}^{2}=77 \%$ ). Additionally, one RCT did not statistically analyze the pulmonary toxicity but reported similar incidences between the amifostine and no amifostine groups, three non-RCTs found similar incidences, and one RCT showed similar incidences of dyspnea grade $4 .{ }^{21}$ Due to high statistical heterogeneity and inconsistent outcomes for both esophageal and pulmonary end-points, the efficacy of amifostine in these settings is yet to be determined.

\section{Amifostine Use in Neutropenia}

Contrariwise, there is recent data that amifostine may be useful in certain situations and ASCO continues to recommend consideration of its use in specific populations. It suggests that amifostine may continue to be considered to reduce Grade 3 or 4 chemotherapy-associated neutropenia. ${ }^{4}$ There were 11 randomized controlled trials since the 2002 recommendation, and overall, data were inconsistent regarding neutropenia. ${ }^{5-12,22-24}$ However, because eight of the smaller trials found no difference $e^{5,6,8-10,12,22,23}$ and one large trial reported a significant difference in lowering frequency of grade 3 or 4 neutropenia, ${ }^{11}$ the panel continues to consider amifostine as an option. ${ }^{4}$ These guidelines do 
not specify if amifostine should be used instead of other more established prophylactic measures such as growth factors and dose reduction for chemotherapy-induced neutropenia or along with it.

\section{Amifostine Use in Xerostomia}

Similarly, the ASCO 2008 update continues to recommend the use of amifostine in prevention of radiation therapy-associated toxicities such as xerostomia to decrease the incidence of acute and late xerostomia. ${ }^{4}$ This recommendation was primarily based on a handful of studies including a prospective, randomized phase II study in 91 patients, which found that at the 6 month mark, the occurrence of grade 2 or greater late xerostomia varied greatly depending amongst patients who did not receive amifostine, those who received amifostine at a dose of 200 $\mathrm{mg} / \mathrm{m}^{2}$ thrice weekly, and those who received amifostine at a dose of $200 \mathrm{mg} / \mathrm{m}^{2}$ daily five times weekly (74\% vs. $67 \%$ vs. $52 \%$; $p=0.03) .{ }^{19}$ In another study $(n=67)$, the incidence of grade 2 or greater xerostomia reduced from $75 \%$ to $36 \%$ $(p=0.002)$ and acute xerostomia reduced from $82 \%$ to $39 \%$ $(p=0.01)$ with amifostine. ${ }^{14}$ It was also seen that parotid function returned to normal quicker in the amifostine arm than the control arm (36.3\% vs $9.1 \%, \mathrm{p}=0.034) .{ }^{14}$ In a prospective, randomized phase III trial investigating the use of amifostine in 303 patients with head-and-neck cancer who received once-daily radiotherapy for 5-7 weeks, the incidence of grade 2 or greater xerostomia at six months in the amifostine group was $4 \%$ compared to $24 \%$ in the control $(p=0.065) .{ }^{25}$ Amifostine use is recommended only for prophylactic use for xerostomia within the setting of radiation therapy and not for patients receiving concurrent radiation and platinum-based radiotherapy. ${ }^{4}$

\section{Amifostine Use in Nephrotoxicity}

ASCO maintains that amifostine may be considered for primary prevention of nephrotoxicity in patients receiving cisplatin-based chemotherapy. There has been no change since the 2002 recommendation as no new data has examined the incidence of nephrotoxicity in patients receiving amifostine. ${ }^{4}$ The 2002 ASCO guidelines recommended the use of amifostine in patients receiving cisplatin for ovarian cancer or NSCLC. This was based on several studies where higher than normal doses of cisplatin were used in these patients. ${ }^{26}$ In one phase II trial, amifostine was added to cisplatin and vinorelbine for the treatment of 25 advanced NSCLC. The median age of patients were 57 years (range, 38-70) and was found that $12 \%$ of patients had reversible grade 3 nephrotoxicity and $28 \%$ of patients developed grade 2 nephrotoxicity with $80 \%$ of patients returning within $20 \%$ of baseline creatinine clearance before their next scheduled dose. ${ }^{27}$ Similarly in a study looking at effects of amifostine in 25 patients receiving high dose cisplatin $\left(120 \mathrm{mg} / \mathrm{m}^{2}\right)$ and vinblastine, it was found that $12 \%$ of patients developed reversible grade 3 nephrotoxicity. ${ }^{28}$ Additionally, in a phase III study evaluating 242 advanced ovarian cancer patients receiving cyclophosphamide and cisplatin, amifostine reduced a cumulative toxicity, as well as nephrotoxicity $(\mathrm{p}=0.001){ }^{29}$ These studies demonstrate amifostine's nephroprotective effects. Amifostine has been thought to be particularly relevant in patients with high risk for renal toxicity such as elderly patients. ${ }^{17}$ This has prompted experts to recommend the prophylactic use of amifostine, along with hydration, magnesium supplementation, and low-dose regimens as the prevention and treatment strategies for cisplatin-induced renal toxicity in the elderly. ${ }^{30}$ However, it should be noted that many elderly patients $(21-27 \%$ per treatment cycle) experience transient, systolic hypotension, which is one of the doselimiting toxicities of amifostine. Also, $69.2 \%$ of the patients reported at least one symptomatic hypotensive episode. Interruption of amifostine infusion is seen more often in the elderly population, some of whom cannot restart the treatment. ${ }^{30}$ In addition, amifostine used in patients with acute kidney injury with greater than $40 \%$ reduction in creatinine clearance or in patients with acute kidney injury with greater than 30 to $40 \%$ reduction in glomerular filtration resulted in further decline in creatinine clearance by up to $10 \%$ reduction after amifostine use. ${ }^{31}$

In addition to inconsistent data supporting efficacy, there are significant toxicities associated with amifostine, which warrants extensive discussion with patients before considering the use of this agent. Common toxicities include acute hypotension (62\%, all grades, per patient), nausea and vomiting (96\%, all grades, per patient). Amifostine is hydrolyzed by alkaline phosphatases that are enriched in normal tissues to the active cytoprotective free thiol metabolite. These ubiquitous alklaline phosphatases are present in the endothelium, which leads to these undesirable side effects and has resulted in the use of amifostine falling out of favor. ${ }^{32}$ When given with radiation therapy, the recommended amifostine dose is $200 \mathrm{mg} / \mathrm{m}^{2} / \mathrm{d}$, given as a slow IV push over 3 minutes, 15 to 30 minutes before each fraction of radiation therapy. ${ }^{1,4}$ Many patients require antiemetics prior to and in conjunction with the administration of amifostine due to the high nausea emetic potential. ${ }^{1,4}$ Blood pressure should be measured just before and immediately after the 3-minute amifostine infusion. ${ }^{4}$ Hypotension associated with amifostine at this dose is less frequent, but still requires close monitoring. ${ }^{4}$ Lower doses have fewer adverse effects.

Currently, the only FDA approved indications for amifostine use is for prophylaxis against nephrotoxicity and radiation-induced mucositis. ${ }^{1}$ While the use of amifostine may be considered in reduction of grade 3 or 4 neutropenia and acute and late xerostomia in certain patient groups, 
they are not FDA-indicated uses of amifostine., ${ }^{1,4-12,14,19,22-24}$ The approved dose and administration of amifostine with chemotherapy is $910 \mathrm{mg} / \mathrm{m}^{2}$ intravenously over 15 minutes, 30 minutes before chemotherapy. ${ }^{1}$ Alternate strategies for prevention of nephrotoxicity are lowering the dose of cisplatin while increasing the frequency to achieve the same total target dose, aggressive hydration, and alternative treatments in patients with renal impairment such as carboplatin. ${ }^{33,34}$ Similarly use of growth factors and adjustment of chemotherapy doses are effective in reducing the incidence of chemotherapy-induced neutropenia. ${ }^{4}$ However, in a recent study comparing high dose cisplatin every 3 weeks vs low dose cisplatin every week, it was found that median overall survival of patients was 5.61 years $(95 \% \mathrm{CI}=4.58-7.69)$ and 3.7 years $(95 \% \mathrm{Cl}$ = 3.1-4.79) respectively. As such, it may be more harm to increase the frequency and lower the dose of cisplatin for overall survival. ${ }^{34,35}$

In summary, the role of amifostine in preventing chemotherapy-related side effects including nephrotoxicity is neither a myth nor a matter-of-fact. It continues to be a mystery with conflicting data derived from sub-optimally conducted studies. It is not surprising that it has fallen out of favor and is no longer used in most institutions. In fact, the drug is on backorder due to lack of demand. Despite major advances in cancer treatments, chemotherapeutic agents remain the backbone of many cancer protocols even today and acute as well as chronic toxicities of these agents are of renewed interest because of increasing survival of cancer patients. Re-exploring the role of amifostine particularly as a prophylactic agent to prevent nephrotoxicity from cisplatin through properly conducted clinical trials would be extremely beneficial while addressing cancer survivorship.

\section{References}

1. Amifostine [package insert]. Nashville, TN: Cumberland Pharmaceuticals Inc.; 2019.

2. Budd GT, Ganapathi R, Adelstein DJ, et al: Randomized trial of carboplatin plus amifostine versus carboplatin alone in patients with advanced solid tumors. Cancer 80:1134-1140, 1997.

3. Betticher DC, Anderson H, Ranson M, et al. Carboplatin combined with amifostine, a bone marrow protectant, in the treatment of non-smallcell lung cancer: a randomised phase II study. Br J Cancer. 1995 Dec; 72(6): 1551-5. doi: 10.1038/bjc.1995.546. PMID: 8519676; PMCID: PMC2034079.

4. Hensley ML, Hagerty KL, Kewalramani T, et al. American Society of Clinical Oncology 2008 clinical practice guideline update: use of chemotherapy and radiation therapy protectants. J Clin Oncol. 2009; 27(1): 127-145. doi: 10.1200/JC0.2008.17.2627.

5. Antonadou D, Throuvalas N, Petridis A, et al. Effect of amifostine on toxicities associated with radiochemotherapy in patients with locally advanced non-small-cell lung cancer. Int J Radiat Oncol Biol Phys. 2003 Oct 1; 57(2): 402-8. doi: 10.1016/s0360-3016(03)00590-x.

6. Bernstein ML, Devidas M, Lafreniere D, et al; Pediatric Oncology Group; Children's Cancer Group Phase II Study 9457; Children's
Oncology Group. Intensive therapy with growth factor support for patients with Ewing tumor metastatic at diagnosis: Pediatric Oncology Group/Children's Cancer Group Phase II Study 9457--a report from the Children's Oncology Group. J Clin Oncol. 2006 Jan 1; 24(1): 152-9. doi: 10.1200/JC0.2005.02.1717.

7. Gold MA, Walker JL, Berek JS, et al. Amifostine pretreatment for protection against topotecan-induced hematologic toxicity: results of a multicenter phase III trial in patients with advanced gynecologic malignancies. Gynecol Oncol. 2003 Aug; 90(2): 325-30. doi: 10.1016/ s0090-8258(03)00319-6.

8. Hwang WY, Koh LP, Ng HJ, et al. A randomized trial of amifostine as a cytoprotectant for patients receiving myeloablative therapy for allogeneic hematopoietic stem cell transplantation. Bone Marrow Transplant. 2004 Jul; 34(1): 51-6. doi: 10.1038/sj.bmt.1704521.

9. Kanat O, Evrensel T, Baran I, et al. Protective effect of amifostine against toxicity of paclitaxel and carboplatin in non-small cell lung cancer: a single center randomized study. Med Oncol. 2003; 20(3): 237-45. doi: 10.1385/M0:20:3:237.

10. Leong SS, Tan EH, Fong KW, et al. Randomized double-blind trial of combined modality treatment with or without amifostine in unresectable stage III non-small-cell lung cancer. J Clin Oncol. 2003 May 1; 21(9): 1767-74. doi: 10.1200/JC0.2003.11.005. PMID: 12721253.

11. Lorusso D, Ferrandina G, Greggi S, et al. Multicenter Italian Trials in Ovarian Cancer investigators. Phase III multicenter randomized trial of amifostine as cytoprotectant in first-line chemotherapy in ovarian cancer patients. Ann Oncol. 2003 Jul; 14(7): 1086-93. doi: 10.1093/ annonc/mdg301.

12. Spencer A, Horvath N, Gibson J, et al. Australasian Leukemia and Lymphoma Group. Prospective randomised trial of amifostine cytoprotection in myeloma patients undergoing high-dose melphalan conditioned autologous stem cell transplantation. Bone Marrow Transplant. 2005 May; 35(10): 971-7. doi: 10.1038/sj.bmt.1704946.

13. De Vos FY, Bos AM, Schaapveld M, et al. A randomized phase II study of paclitaxel with carboplatin +/- amifostine as first line treatment in advanced ovarian carcinoma. Gynecol Oncol. 2005 Apr; 97(1): 60-7. doi: 10.1016/j.ygyno.2004.11.052.

14. Veerasarn V, Phromratanapongse P, Suntornpong N, et al. Effect of Amifostine to prevent radiotherapy-induced acute and late toxicity in head and neck cancer patients who had normal or mild impaired salivary gland function. J Med Assoc Thai. 2006 Dec; 89(12): 2056-67.

15. Gu J, Zhu S, Li X, et al. Effect of amifostine in head and neck cancer patients treated with radiotherapy: a systematic review and metaanalysis based on randomized controlled trials. PLoS One. 2014 May 2; 9(5): e95968. doi: 10.1371/journal.pone.0095968. PMID: 24788761; PMCID: PMC4008569.

16. Albers JW, Chaudhry V, Cavaletti G, et al. Interventions for preventing neuropathy caused by cisplatin and related compounds. Cochrane Database Syst Rev. 2014 Mar 31; (3): CD005228. doi: 10.1002/14651858.CD005228.pub4.

17. Jellema AP, Slotman BJ, Muller MJ, et al. Radiotherapy alone, versus radiotherapy with amifostine 3 times weekly, versus radiotherapy with amifostine 5 times weekly: A prospective randomized study in squamous cell head and neck cancer. Cancer. 2006 Aug 1; 107(3): 544-53.

18. Braaksma M, Levendag P. Tools for optimal tissue sparing in concomitant chemoradiation of advanced head and neck cancer: subcutaneous amifostine and computed tomography-based target delineation. Semin Oncol. 2002 Dec; 29(6 Suppl 19): 63-70.

19. Buentzel J, Micke O, Adamietz IA, et al. Intravenous amifostine during chemoradiotherapy for head-and-neck cancer: a randomized placebo-controlled phase III study. Int J Radiat Oncol Biol Phys. 2006 Mar 1; 64(3): 684-91 
20. Vacha P, Fehlauer F, Mahlmann B, et al. Randomized phase III trial of postoperative radiochemotherapy $+/$ - amifostine in head and neck cancer. Is there evidence for radioprotection? Strahlenther Onkol. 2003 Jun; $179(6)$ : 385-9.

21. Devine A, Marignol L. Potential of Amifostine for Chemoradiotherapy and Radiotherapy-associated Toxicity Reduction in Advanced NSCLC: A Meta-Analysis. Anticancer Res. 2016; 36(1): 5-12.

22. Antonadou D, Pepelassi M, Synodinou M, et al. Prophylactic use of amifostine to prevent radiochemotherapy-induced mucositis and xerosto- mia in head-and-neck cancer. Int J Radiat Oncol Biol Phys 52: 739-747, 2002.

23. Komaki R, Lee JS, Milas L, et al. Effects of amifostine on acute toxicity from concurrent chem- otherapy and radiotherapy for inoperable non- small-cell lung cancer: Report of a randomized comparative trial. Int J Radiat Oncol Biol Phys 58: 1369-1377, 2004.

24. Movsas B, Scott C, Langer C, et al. Randomized trial of amifostine in locally advanced non-small-cell lung cancer patients receiving chemotherapy and hyperfractionated radiation: Radiation therapy oncol- ogy group trial 98-01. J Clin Oncol 23: 2145-2154, 2005.

25. Wasserman TH, Brizel DM, Henke M, et al. Influence of intravenous amifostine on xerostomia, tumor control, and survival after radiotherapy for head-and- neck cancer: 2-year follow-up of a prospective, randomized, phase III trial. Int J Radiat Oncol Biol Phys. 2005 Nov 15; 63(4): 985-90. doi: 10.1016/j.jirobp.2005.07.966. PMID: 16253773.

26. Schuchter LM, Hensley ML, Meropol NJ, et al. American Society of Clinical Oncology Chemotherapy and Radiotherapy Expert Panel. 2002 update of recommendations for the use of chemotherapy and radiotherapy protectants: clinical practice guidelines of the American Society of Clinical Oncology. J Clin Oncol. 2002 Jun 15; 20(12): 2895903. doi: $10.1200 / J C 0.2002 .04 .178$.

27. Gridelli C, Cigolari S, et al. Amifostine plus cisplatin plus vinorelbine in the treatment of advanced non small cell lung cancer: a multicenter phase II study. Lung Cancer. 2000 Jun; 28(3): 237-44. doi: 10.1016/ s0169-5002(99)00131-2. PMID: 10812192.
28. Schiller JH. High-dose cisplatin and vinblastine plus amifostine for metastatic non-small cell lung cancer. Semin Oncol. 1996 Aug; 23(4 Suppl 8): 78-82. PMID: 8783672.

29. Kemp G, Rose P, Lurain J, et al. Amifostine pretreatment for protection against cyclophosphamide-induced and cisplatin-induced toxicities: results of a randomized control trial in patients with advanced ovarian cancer. J Clin Oncol. 1996 Jul; 14(7): 2101-12. doi: 10.1200/ JC0.1996.14.7.2101. PMID: 8683243.

30. Duan Z, Cai G, Li J, Chen X. Cisplatin-induced renal toxicity in elderly people. Ther Adv Med Oncol. 2020;12:1758835920923430. Published 2020 May 18. doi:10.1177/1758835920923430.

31. Logothetis CJ, Assikis V, Sarriera JE. Diagnosis, Treatment, and Prevention of Nephrotoxicity of Cancer Therapeutic Agents. In: Kufe DW, Pollock RE, Weichselbaum RR, et al., editors. Holland-Frei Cancer Medicine. 6th edition. Hamilton (ON): BC Decker; 2003. Available from: https://www.ncbi.nlm.nih.gov/books/NBK12686/

32. Molkentine JM, Fujimoto TN, Horvath TD, et al. Enteral Activation of WR-2721 Mediates Radioprotection and Improved Survival from Lethal Fractionated Radiation. Sci Rep. 2019 Feb 13; 9(1): 1949. doi: 10.1038/s41598-018-37147-9. PMID: 30760738.

33. Jellema AP, Slotman BJ, Muller MJ, et al. Radiotherapy alone, versus radiotherapy with amifostine 3 times weekly, versus radiotherapy with amifostine 5 times weekly: A prospective randomized study in squamous cell head and neck cancer. Cancer. 2006 Aug 1; 107(3): 544-53. doi: 10.1002/cncr.22020. PMID: 16804929.

34. Cisplatin solution for injection [prescribing information]. Schaumburg, IL: Athenex; June 2017.

35. McCusker MG, Mehra R, Molitoris JK, et al. Cisplatin every three weeks versus weekly cisplatin or carboplatin with definitive radiotherapy for squamous cell carcinoma of the head and neck is associated with improved overall survival in a representative national population. J Clin Oncol. 2020 May; 38(15): 6536-6536. DOI: 10.1200/ JC0.2020.38.15_suppl.6536. 